\title{
Atividade antimicrobiana do óleo-resina produzido pela copaiba - Copaifera multijuga Hayne (Leguminosae)
}

\author{
Davidy Eduardo Mendonça, Sideney Becker Onofre* \\ Universidade Paranaense, UNIPAR, Campus de Francisco Beltrão, PR, \\ Av Julio Assis Cavalheiro 2000, Bairro Industrial, 85601-060 Francisco Beltrão-PR, Brasil
}

\begin{abstract}
RESUMO: A pesquisa de plantas com fins medicinais tem grande importância para a comunidade médica, uma destas é o óleo-resina extraído da copaíba, Copaifera multijuga Hayne, o qual é natural da região Amazônica onde é encontrado uma grande diversidade dessa espécies. Seu uso medicinal, tão difundido o torna o fitofármaco mais usado e conhecido pelas populações mais pobres da região Norte do Brasil, sendo utilizado como diurético, laxativo, antitetânico, antiblenorrágico, anti-reumático, anti-séptico do aparelho urinário, antiinflamatório, antitussígeno, cicatrizante e remédio para o combate ao câncer. O presente trabalho apresenta os resultados da avaliação da atividade antimicrobiana deste óleo, onde foi avaliado pela a técnica de difusão em ágar em meio Muller-Hinton. As cepas avaliadas foram: Escherichia coli ATCC 25922, Staphylococcus aureus ATCC 25923 e Pseudomonas aeruginosa ATCC 9027. As placas forma incubadas em estufas por $24 \mathrm{~h}$ em temperatura de $35^{\circ} \mathrm{C}$. Como padrões foram utilizados os antibióticos amoxicilina (AMO$10 \mathrm{mg} /$ disco), cloranfenicol (CLO-30 mg/disco) e tetraciclina (TET-30 mg/disco). Os resultados mostraram que o óleo de copaíba possui capacidade de inibir o crescimento das três bactérias avaliadas, apresentando com isso uma concentração inibitória mínima de 1,56, 3,12 e 12,5\% para E. coli, $S$. aureus e $P$. aeruginosa, respectivamente.
\end{abstract}

Unitermos: Óleo de copaíba, Copaifera multijuga, Leguminosae, atividade antimicrobiana, MIC.

\begin{abstract}
Antimicrobial activity of the oil-resin produced by copaiba copaifera multijuga Hayne (Leguminosae)". The research of plants with medicinal purposes has great importance for the medical community, one of these is the oil-resin extracted of copaíba, Copaifera multijuga Hayne, which is natural of the Amazon region where a great diversity of this species is found. Its medicinal use, the way it is widely spread out, becomes it the phytopharmacs most used and known by the poor populations at the North region of Brazil, being used as diuretic, laxative, antitetanic, antiblenorragic, anti-rheumatic, anti-septic for urinary system, anti-inflammatory, anti-cough, cicatrizing and medicine for the combat to the cancer. The present work shows the evaluation results of this oil antimicrobial activity by the technique of diffusion in agar in Muller-Hinton ambience. The evaluated strains were: Escherichia coli ATCC 25922, 25923 Staphylococcus aureus ATCC and Pseudomonas aeruginosa ATCC 9027. The plates were incubated in hot houses for $24 \mathrm{~h}$ under temperature of $35{ }^{\circ} \mathrm{C}$. Amoxicillin antibiotics (AMO-10 mg/disco), cloranfenicol (CLO-30 mg/ disco) and tetracycline used (TET-30 mg/disco) as being standard. The results showed that the oil has the capacity to inhibit the growth of three evaluated bacteria, presenting a minimum inhibitory concentration of 1,56, 3,12 and $12.5 \%$ for E. coli, S. aureus and P. aeruginosa, respectively.
\end{abstract}

Keywords: Copaíba oil, Copaifera multijuga, Leguminosae, antimicrobial activity, MIC.

\section{INTRODUÇÃO}

Chamada de copaíba ou copahu pelos indígenas, o óleo da copaíba era bastante utilizado entre os índios quando os portugueses chegaram ao Brasil. Tudo indica que o uso desse óleo veio da observação do comportamento de certos animais que, quando feridos, esfregavam-se nos troncos das copaibeiras. Os índios o utilizavam principalmente como cicatrizante e no umbigo de recém-nascidos para evitar o mal-dos-sete-dias. Os guerreiros quando voltavam de suas lutas untavam o corpo com o óleo da copaíba e se deitavam sobre esteiras suspensas e aquecidas para curar eventuais ferimentos (Ferreira, 1999; Leite, 2001).

O uso do óleo de copaíba, assim como de outras drogas indígenas entre os brancos, foi difundido no século XVII, quando os primeiros médicos residentes no Brasil tentavam contornar a escassez de remédios cujo suprimento à Colônia era irregular (Ferreira, 1999).

A copaíba (Copaifera multijuga), ou copaibeira, é uma árvore de grande porte da família Leguminosae encontrada em todo o Brasil. O gênero Copaifera possui mais de 25 espécies, sendo a maioria encontrada na 
América do Sul. Vulgarmente são chamadas de copaíba, pau-d'óleo, copaíba-roxa e copaíba-mari-mari. Árvore mede até 36 metros de altura possui copa densa, casca lisa e fruste reto; produz de 2 a $3 \mathrm{~kg}$ de sementes. A floração ocorre em janeiro a março e os frutos são coletados em março a agosto. Há mudança foliar em dezembro, com perda parcial das folhas no mês anterior à floração (Yunes \& Cechinel Filho, 2001).

Os habitantes da floresta identificam essa árvore pelo forte aroma de sua casca e pela presença de pequenos animais silvestres que se alimentam de seus frutos. $\mathrm{Na}$ região Amazônica há uma grande diversidade de espécies. Podem ser encontradas nas matas de terra firme e nos solos argilosos e arenosos, em todos os estados da região. As espécies são muito semelhantes entre si, principalmente no tamanho da árvore sempre muito grande, formando o teto da floresta da mata virgem (Leite, 2001).

A espécie mais estudada é a Copaifera multijuga Hayne. Ocorre desde o médio Tapajós até a Amazônia Ocidental (Amazonas, Acre e Rondônia). Está presente também, nas regiões sul de Roraima e norte de Mato Grosso. Inventários florestais realizados em algumas áreas de ocorrência na região indicam a presença de árvores adultas em densidades que variam na média de 0,1143 a 2 indivíduos por hectare (Leite, 2001).

A Copaifera multija Hayne é uma árvore grande, podendo chegar a 36 metros de altura, de copa densa e casca lisa $(0,5 \mathrm{~cm}-2,0 \mathrm{~cm}$ de espessura), fuste reto (diâmetro entre 40 a $50 \mathrm{~cm}$ ), diferenciando-se das espécies do mesmo gênero pelas flores maiores, brancas e pelo tamanho dos folíolos e dos frutos (Leite, 2001).

Os frutos são vagens avermelhadas $(3,5 \mathrm{~cm}$ de comprimento, $3 \mathrm{~cm}$ de largura e 1,5 de espessura) com 1 ou 2 sementes. A árvore de copaíba produz 2 a $3 \mathrm{~kg}$ de sementes, apresentando, para essa espécie, de 1200 a 2000 sementes férteis por árvores. As sementes são ovais, quase globosas, com arilo amarelo intenso. A floração dessa espécie de copaíba acontece de janeiro a março, e os frutos são coletados de março a agosto. Há mudança foliar em dezembro, com perda parcial das folhas no mês anterior à floração (Azevedo et al., 2004).

Estudos farmacológicos com o óleo de copaíba mostram que o uso do óleo pelos índios é plenamente justificado. Avaliação in vivo e in vitro vem demonstrando que os óleos de várias espécies de copaíferas possuem atividade antiinflamatória, cicatrizante, antiedematogênica antitumoral, tripanossomicida e bactericida. O óleo de propriedades quase mágicas e que causou espanto dos primeiros europeus quando viram árvores tropicais exuberantes jorrarem óleo aromático, pode ser sintetizado na descrição feita por Pero Magalhães Gandavo, um de nossos cronistas mais importantes, em seu livro "História da Província de Santa Cruz", de (1768), citado por Soares et al. (2003).

Segundo a Azevedo et al. (2004) e Agra et al. (2007; 2008), as indicações etnofarmacologicas mais usuais do óleo de copaíba são: a) para as vias urinárias, como antiblenorrágico, antiinflamatório, antigonorréico, antiséptico, estimulante e no tratamento de cistite, incontinência urinaria e sífilis; b) para as vias respiratórias, antiasmático, expectorante, no tratamento de bronquite, inflamação da garganta, hemoptise, pneumonia e sinusite; c) para as infecções da derme e mucosa, como dermatites, eczemas, psoríases e ferimentos; d) para ulceras e feridas do útero e) outras finalidades, como afrodisíaco, antitetânico, antireumático, anti-herpético, anticancerígeno, antitumoral (tumores da próstata), no tratamento de leishmaniose e da leucorréia, contra paralisia, dores de cabeça e picadas de cobra.

Assim considerando estas informações pode-se avaliar que o potencial do óleo resina da copaíba apresenta uma atividade antimicrobiana significativa para diversos microrganismos patógenos ao homem (Packer \& Luz, 2007; Vasconcelos et al., 2008).

Quanto aos efeitos antiinflamatórios, gastroprotetor, analgésico e antitumoral do óleo resina de copaíba como também o seu potencial como antioxidante, inseticida e repelente de insetos já são comprovados em diversos estudos (Azevedo et al, 2004).

Atualmente, constata-se que os óleos de copaíba vêm sendo vendidos em muitas farmácias de todo o país, adulterados com óleos vegetais, principalmente o de soja. Um trabalho conjunto da Vigilância Sanitária deve ser estimulado, no sentido de fiscalizar a venda dos fitoterápicos/fitoquímicos e combater os falsificadores (Soares et al., 2003; Barbosa et al., 2009).

Quanto as características físico-químicas do óleo-resina da Copaifera multijuga Hayne, podemos afirmar que é um líquido transparente, viscoso e fluido, com cheiro forte e odor de cumarina, sabor acre e amargo. Pode ser armazenado por até 2 anos sem alterar as suas propriedades podendo transformar-se em resina se exposto ao ar e à luz. As características do óleo-resina variam com a procedência da copaíba e do tipo de solo (Plowden, 2003)

Nas avaliações das propriedades físico-químicas do óleo-resina mostraram uma densidade de 0,8925 g/ $\mathrm{m}^{3}$, índice de acidez de 0,5; índice de saponificação de 0,9, índice de acetila de 10,6; índice de iodo de 147,2 e insaponificação de 64,8\% (Sebrae/Suframa/MMA, 1998).

Estudos fitoquímicos recentes mostram que os óleos de copaíba são misturas de sesquiterpenos e diterpenos. O ácido copálico e os sesquiterpenos $\beta$-cariofileno e o $\alpha$-copaeno são os principais componentes do óleo. O ácido copálico, encontrado em todos os óleos de copaíba até hoje estudados, talvez possa vir a ser usado como um biomarcador para a autenticidade desses óleos (Soares et al., 2003).

Os principais componentes do óleo de copaíba são: $\alpha$-cubeno, de 2,9 a 3,2\%; $\alpha$-copaeno de 7,9 a $18,7 \%$; $\beta$-cariofileno de 46,1 a 47,0\%; $\alpha$-humuleno de 5,4 a 5,6\%; $\beta$-bisaboleno de 5,9 a 6,1\%; cadineno de 6,0-6,2\%; entre outros compostos não identificados, que gira em torno de 
13,5\% (Soares Maia et al.,1978, Cascon \& Gilbert, 2000).

Assim, este estudo terá como objetivo verificar in vitro a atividade antimicrobiana do óleo resina de copaíba - Copaifera multijuga, sobre bactérias como Escherichia coli, Staphylococcus aureus e Pseudomonas aeruginosa, utilizando para isso o método de difusão em disco, além de determinar a sua Concentração Inibitória Mínima (CIM).

\section{MATERIAL E MÉTODOS}

O óleo resina de copaíba foi obtido na região de Aripuanã, MT no ano de 2006, nas coordenadas geográficas de $9^{\circ} ; 10^{\prime} ; 45^{\prime} \mathrm{S}$ e $60^{\circ} ; 37^{\prime} ; 50^{\prime} \mathrm{W}$, sendo que a sua coleta foi realizada no mês de maio do mesmo ano. Após a coleta esse material foi transportado em frasco âmbar e armazenado na temperatura de $\pm 4{ }^{\circ} \mathrm{C}$ para posterior análise.

A atividade antimicrobiana foi realizada, utilizando a técnica de difusão em disco. O princípio deste método baseia-se na inoculação em superfície de um ágar de solução padronizada de microrganismo específico. Sobre este são colocados discos de papéis impregnados previamente com soluções das amostras que se deseja investigar a atividade antimicrobiana. As substâncias impregnadas nos discos de papel difundem-se no meio de cultura e, se a amostra em questão apresentar atividade inibitória sobre o microrganismo testado, forma-se um halo de não crescimento ao redor do disco impregnado. Após o período de incubações, respeitadas as condições específicas para o microrganismo, às zonas de inibição são medidas em volta de cada disco (Isenberg, 1992; Vandepitte et al., 1994; Koneman et al., 1997). Para a realização dos ensaios, foram preparados escalas de diluições dos óleos, em tubos de ensaio numerados de 1 a 10 conforme as diferentes concentrações. Para isso foi utilizado dimetilsulfóxido (DMSO) como solvente. As concentrações preparadas foram: 100, 50, 25, 12, 5, 6, 25, $3,12,1,56,0,78,0,39$ e $0,19 \%$. No tubo 1 foi colocado 1 $\mathrm{mL}$ do óleo puro e nos demais tubos (2 a 10) $0,5 \mathrm{~mL}$ de DMSO à $1 \mathrm{~mL}$ do tubo anterior.

Após a obtenção das concentrações de 100, 50, $25,12,5,6,25,3,12,1,56,0,78,0,39$ e $0,19 \%$, discos de papel filtro de $6 \mathrm{~mm}$ de diâmetro foram impregnados por saturação.

O meio de cultura utilizado para o teste de atividade antimicrobiana foi o ágar Mueller-Hinton (MH) - preparado a partir do meio desidratado de acordo com a recomendação do fabricante pronto para o uso. Nas avaliações foram utilizados cepas de Staphylococcus aureus ATCC 25923 (suscetível à oxacilina e penicilina), Escherichia coli ATCC 25922 (beta-lactamase negativa) e Pseudomonas aeruginosa ATCC 9027. As culturas microbianas foram padronizadas em $10^{8}$ células $/ \mathrm{mL}$, estimadas por comparação ao tubo 0,5 da escala de MacFarland.

As suspensões bacterianas foram inoculadas em placas contendo ágar Mueller-Hinton com o auxílio de uma alça de Drigalski. Após este procedimento, os discos previamente preparados foram transferidos para meios contendo os inóculos. As placas foram incubadas a $35 \pm 1$ ${ }^{\circ} \mathrm{C}$ durante $24 \mathrm{~h}$. Passado este período, as placas foram inspecionadas quanto à presença de halos de inibição (medidos em mm). Todos os ensaios foram realizados em triplicata e tiveram como controle positivo o antibiótico cloranfenicol (CLO) $10 \mu \mathrm{g} /$ disco.

Os diâmetros dos halos de inibição foram interpretados de acordo com os critérios de interpretação preconizados pelo Committee For Clinical Laboratory Standards International (1997). A CIM (Concentração Inibitória Mínima) foi considerada como a menor concentração do óleo testado capaz de inibir o desenvolvimento bacteriano.

Todas as atividades foram realizadas em triplicatas e os dados obtidos, foram avaliados por meio de análise de variância.

\section{RESULTADOS E DISCUSSÃO}

Os resultados obtidos com a atividade antimicrobiana do óleo resina de copaíba estão sumarizados na Tabela 1 .

Tabela 1. Atividade antimicrobiana do óleo resina de copaíba (Copaifera multijuga).

\begin{tabular}{cccc}
\hline $\begin{array}{c}\text { Concentração } \\
\text { do óleo (\%) }\end{array}$ & E. coli & P. aeruginosa & S. aureus \\
\hline 100 & $12 \pm 2,23 *$ & $13 \pm 1,97$ & $13 \pm 2,65$ \\
50 & $12 \pm 2,45$ & $12 \pm 2,06$ & $11 \pm 1,98$ \\
25 & $11 \pm 1,87$ & $10 \pm 1,78$ & $10 \pm 2,54$ \\
12,5 & $8 \pm 1,23$ & $9 \pm 1,65$ & $9 \pm 1,89$ \\
6,25 & $8 \pm 1,45$ & $\mathrm{R}$ & $7 \pm 1,22$ \\
3,12 & $8 \pm 1,56$ & $\mathrm{R}$ & $7 \pm 1,23$ \\
1,56 & $8 \pm 1,34$ & $\mathrm{R}$ & $\mathrm{R}$ \\
0,78 & $\mathrm{R}$ & $\mathrm{R}$ & $\mathrm{R}$ \\
0,39 & $\mathrm{R}$ & $\mathrm{R}$ & $\mathrm{R}$ \\
0,19 & $\mathrm{R}$ & $\mathrm{R}$ & $\mathrm{R}$ \\
CLO-10 & $26 \pm 3,45$ & $19 \pm 2,67$ & $25 \pm 4,21$ \\
\hline
\end{tabular}

* Halos determinados em mm. R = Resistente - CLO-10 (cloranfenicol $10 \mu \mathrm{g} /$ disco).

Com base nos resultados obtidos, pode-se constatar que o óleo de copaíba apresentou um potencial de inibição do crescimento bacteriano sobre as três bactérias patogênicas avaliadas. Sua atividade antimicrobiana variou de acordo com a diluição do óleo, sendo que nas concentrações de $100 \%$ a $1,56 \%$ houve inibição do crescimento dos patógenos avaliados. 
Tabela 2. Concentrações inibitórias mínima do óleo resina de copaíba (Copaifera multijuga) sobre as bactérias avaliadas.

\begin{tabular}{lcc}
\hline \multicolumn{1}{c}{ Microrganismo } & CIM (\%) & Halo formado \\
\hline Escherichia coli & 1,56 & $8 \pm 1,34^{*}$ \\
Staphylococcus aureus & 3,12 & $7 \pm 1,23$ \\
Pseudomonas aeruginosa & 12,5 & $9 \pm 1,65$ \\
\hline
\end{tabular}

* Halos determinados em mm.

Quando avaliamos o comportamento do óleo sobre o crescimento da bactéria Gram negativa $E$. coli, verificamos que a maior inibição ocorreu com a concentração de $100 \%$, isto é o óleo resina puro, induzindo um halo de inibição de $12 \pm 2,23 \mathrm{~mm}$; a partir daí, os valores foram declinando, chagando a $8 \pm 1,34 \mathrm{~mm}$ na concentração de $1,56 \%$, sendo com isso considerado esta concentração a Concentração Inibitória Mínima (CIM) para o óleo resina de copaíba, sobre a bactéria $E$. coli ATCC-25922. Comparando os resultados obtidos com o antibiótico padrão o cloranfenicol (CLO $10 \mu \mathrm{g} /$ disco) podemos concluir que utilizando o óleo puro, mostrou uma atividade que equivale a 46,15\% desse antimicrobiano.

$\mathrm{Na}$ avaliação do comportamento do óleo sobre a bactéria também Gram negativa Pseudomonas aeruginosa, verificamos, que seu comportamento foi semelhante ao obtido com a E. coli. Os resultados mostram que o crescimento foi inibido na concentração de $100 \%$ do óleo (óleo puro), formando um halo de inibição de 13 $\pm 1,97 \mathrm{~mm}$, o que corresponde a $68,42 \%$ da atividade do cloranfenicol (CLO $10 \mu \mathrm{g} /$ disco), sobre a Pseudomonas aeruginosa. A partir desse resultado, foi verificado que os halos de inibição foram decaindo, até chegar a concentração de $12,5 \%$ onde induziu a formação de um halo de inibição de $9 \pm 1,65 \mathrm{~mm}$, sendo assim essa concentração, considerada a Concentração Inibitória Mínima (CIM) deste óleo resina sobre a bactéria P. aeruginosa ATCC- 9027.

Nos resultados obtidos com a bactéria patogênica Gram positiva, S. aureus, verificou-se que o comportamento do óleo foi semelhante aos resultados obtidos com as bactérias Gram negativas. Foi possível verificar que o halo de inibição foi de $13 \pm 2,65 \mathrm{~mm}$ na concentração de $100 \%$ (óleo puro), decaindo para $11 \pm 1,98,10 \pm 2,54,9 \pm 1,89$, $7 \pm 1,22$ e $7 \pm 1,23 \mathrm{~mm}$, nas concentrações de 50, 25, 12,5, 6,25 e $3,12 \%$, respectivamente. Como esses valores foi possível determinar a Concentração Inibitória Mínima (CIM) do óleo resina de copaíba, sobre a bactéria Gram positiva, Staphylococcus aureus ATCC 25923 (suscetível à oxacilina e penicilina) foi na concentração de $3,12 \%$.

Comparando os resultados obtidos neste trabalho utilizando óleo resina de copaiba, com os resultados obtidos por Bloise (2003), onde utilizou óleos obtidos de Copaiba spp e a mesma metodologia, obteve-se resultados semelhantes, pois os óleos avaliados em ambos os trabalhos, apresentaram atividade antimicrobiana sobre $S$. aureus, E. coli e $P$. aeruginosa.
Em outro trabalho, Biavatti et al. (2006), estudaram a composição do óleo resina de Copaifera multijuga e a atividades antimicrobiana desse óleo sobre S. aureus, E. coli e Streptococcus mutans. Os resultados com a atividade antimicrobiana do óleo de Copaifera multijuga, frente a Streptococcus mutans, foi superior aos obtidos sobre $S$. aureus e $E$. coli, porém em ambos os casos os resultados foram significativos, coincidindo com os nossos resultados.

Trabalhos devem ser desenvolvidos no sentido de padronizar os óleos obtidos no mercado consumidor, pois estudos realizados com óleo de Copaifera multijuga, mostraram variações na composição de óleos coletados de uma mesma árvore, em períodos diversos do ano (verãoinverno). As substâncias detectadas foram basicamente às mesmas, mas suas concentrações variaram (Veiga \& Pinto, 2002). Estudos de atividade antiinflamatória foram realizados e evidenciaram modificações nos perfis das atividades dos dois óleos. Essas variações podem dificultar a generalização da dosagem de uso dos fitoterápicos formulados à base de óleos de copaíba.

Esses achados preliminares, porém promissores, noslevaaintensificaçãodeestudos clínicoscomplementares, assim como a avaliação da ação sinérgica e/ou antagônica destes fitoconstituintes quando usados em associação com outros produtos de origem vegetal ou não, principalmente sobre bactérias multirresistentes, incluindo a possibilidade de estudar os efeitos biológicos ao nível genético e ação desses compostos sobre plasmídeos de resistência a drogas, e linhagens de $S$. aureus de origem humana, contribuindo assim na busca de medidas de controle da resistência aos antimicrobianos.

\section{CONCLUSÕES}

Com base nos resultados obtidos, foi possível, verificar que o óleo de copaíba apresentou capacidade de inibir o crescimento das bactérias E. coli ATCC25922, S. aureus ATCC-25923 e P. aeruginosa ATCC9027, apresentando com isso uma concentração inibitória mínima de 1,56, 3,12 e 12,5\% para E. coli, S. aureus e $P$. aeruginosa, respectivamente.

\section{REFERÊNCIAS}

Agra MF, França PF, Barbosa-Filho JM 2007. Synopsis of the plants known as medicinal and poisonous in Northeast of Brazil. Rev Bras Farmacogn 17: 114-140.

Agra MF, Silva KN, Basílio IJLD, França PF, Barbosa-Filho JM 2008. Survey of medicinal plants used in the region Northeast of Brazil. Rev Bras Farmacogn 18: 472-508.

Azevedo OCR, Wadt PGS, Wadt LHO 2004. Copaíba: Ecologia e Produção de Óleo-Resina. Empresa Brasileira de Pesquisa Agropecuária, Centro de Pesquisa Agroflorestal do Acre Ministério da Agricultura, Pecuária e Abastecimento EMBRAPA. Rio Branco - AC. 
Barbosa KS, Yoshida M, Scudeller VV 2009. Detection of adulterated copaiba (Copaifera multijuga Hayne) oilresins by refractive index and thin layer chromatography. Rev Bras Farmacogn 19: 57-60.

Biavatti MW, Dossin D, Deschamps FC, Lima MP 2006. Análise de óleos-resinas de copaíba: contribuição para o seu controle de qualidade. Rev Bras Farmacogn 16: 230235.

Bloise MI 2003. Óleos vegetais e especialidades da floresta Amazônica. Cosmetics \& Toiletries 15: 46-49.

Cascon V, Gilbert B 2000. Characterization of the chemical composition of oleoresins of Copaifera guianensis Desf., Copaifera duckei Dwyer and Copaifera multijuga Hayne. Phytochemistry 55: 773-778.

Committee For Clinical Laboratory Standards International (CLSI) 1997. Approved standard M2-A7: Performance standards for antimicrobial disk susceptibility tests. Seventh edition. Wayne, PA.

Ferreira LA 1999. Potencial de extração e comercialização do óleo-resina de copaiba (Copaifera spp.): um estudo de caso na Floresta Estadual do Antimary, Acre. São Carlos, 54 p. Dissertação de Mestrado, Ecologia e Manejo de Recursos Naturais, Universidade Federal de São Carlos.

Isenberg HD 1992. Clinical microbiology Procedures Handbook. Washington, D.C: American Society for Microbiology, p. 235-265.

Koneman EW, Allen SD, Janda WN, Schrecknberger PC, Winn Jr WC 1997. Antimicrobial susceptibility testing. In: Color Atlas and text book of diagnostic microbiology. 5.ed. Philadelphia-New York: Lippncott, 398-408 p.

Leite A 2001. Recomendações para o manejo sustentável do óleo de copaíba. Rio Branco: Universidade Federal do Acre. $38 \mathrm{p}$.

Packer JF, Luz MMS 2007. Método para avaliação e pesquisa da atividade antimicrobiana de produtos de origem natural. Rev Bras Farmacogn 17: 102-107.

Plowden C 2003. Production ecology of copaíba (Copaifera spp) oleoresin in the Eastern Brazilian Amazon. Econ Bot 57: 491-501.

Sebrae/Suframa/MMA 1998. Produtos potenciais da Amazônia: Urucum. $236 \mathrm{p}$

Soares JG, Vareão MJC, Wolter Filho W, Mourão AP, Craveiro AAR, Alencar JC 2003. Estudo químico de óleos essenciais, oleaginosas e láticas da Amazônia I. Composição e oxidação do óleo de uma espécie de Copaifera. Acta Amazonica 9: 65-59.

Soares Maia JG, Vareão MJC, Wolter Filho W, Mourão AP, Craveiro AAR, Alencar JC 1978. Estudo químico de óleos essenciais, oleaginosas e láticas da Amazônia I. Composição e oxidação do óleo de uma espécie de Copaifera. Acta Amazonica 9: 45-51.

Vandepitte J, Engbaek K, Piot PE, Heuck CC 1994. Procedimentos laboratoriais em bacteriologia clínica. OMS. Editora Santos, São Paulo. p. 87.

Vasconcelos KRF, Veiga Junior VF, Rocha WC, Bandeira MFCL 2008. Avaliação in vitro da atividade antibacteriana de um cimento odontológico à base de óleo-resina de Copaifera multijuga Hayne. Rev Bras Farmacogn 18 (Supl.): 733-738.

Veiga Jr. F, Pinto AC 2002. O gênero Copaifera L. Quim Nova 25: 273-286.

Yunes RA, Cechinel FV 2001. Breve análise histórica de plantas medicinais: sua importância na atual concepção de fármaco segundo os paradigmas ocidental e oriental. In: Yunes RA, Calixto JB (eds.). Plantas medicinais sob a óptica da química medicinal moderna. Chapecó: Argos. p.17-46. 